\title{
Tumor CTLA-4 overexpression predicts poor survival in patients with nasopharyngeal carcinoma
}

\author{
Pei-Yu Huang ${ }^{1,2, *}$, Shan-Shan Guo ${ }^{1,2, *}$, Yu Zhang ${ }^{1,3, *}$, Jia-Bin Lu' ${ }^{1,3}$, Qiu-Yan Chen ${ }^{1,2}$, \\ Lin-Quan Tang ${ }^{1,2}$, Lu Zhang ${ }^{1,2}$, Li-Ting Liu ${ }^{1,2}$, Li Zhang ${ }^{1,4}$, Hai-Qiang Mai,2 \\ ${ }^{1}$ State Key Laboratory of Oncology in South China, Collaborative Innovation Center for Cancer Medicine, Sun Yat-Sen \\ University Cancer Center, Guangzhou, China \\ ${ }^{2}$ Department of Nasopharyngeal Carcinoma, Sun Yat-Sen University Cancer Center, Guangzhou, China \\ ${ }^{3}$ Department of Pathology, Sun Yat-Sen University Cancer Center, Guangzhou, China \\ ${ }^{4}$ Department of Medical Oncology, Sun Yat-Sen University Cancer Center, Guangzhou, China \\ *These authors contributed equally to this work
}

Correspondence to: Li Zhang, e-mail: zhangli@sysucc.org.cn

Hai-Qiang Mai, e-mail: maihq@sysucc.org.cn

Keywords: CTLA-4, CD28, nasopharyngeal carcinoma, immunohistochemistry, prognostic factor

Received: July 05, 2015

Accepted: January 26, 2016

Published: February 16, 2016

\section{ABSTRACT}

The expression levels of CTLA-4 and CD28 were analyzed in 191 nasopharyngeal carcinoma (NPC) patients diagnosed and treated at our hospital between January 2010 and November 2011. The 3-year overall survival (OS) rate $(91.4 \%$ vs. $81.2 \%$, $p=0.043)$, failure-free survival (FFS) rate $(82.8 \%$ vs. $68.0 \%, p=0.009)$ and distant failure-free survival (D-FFS) rate $(85.8 \%$ vs. $72.3 \%, p=0.006)$ in the low tumor CTLA-4 expression group was higher than in the high tumor CTLA-4 group. There were no differences between the locoregional failure-free survival (LR-FFS) rates in the high and low tumor CTLA-4 expression groups. Moreover, no differences in the OS, FFS, D-FFS, or LR-FFS were observed between the groups with high and low lymphocyte CTLA-4 levels, high and low tumor CD28 levels, or high and low lymphocyte CD28 levels. Cox regression analysis confirmed the prognostic value of tumor CTLA4 expression, particularly for D-FFS, in NPC patients $(p=0.044)$. NPC patients with high tumor CTLA-4 expression had a poorer prognosis than those with low expression.

\section{INTRODUCTION}

Nasopharyngeal carcinoma (NPC) is endemic in southern China and South-East Asia. There are approximately 80,000 incident cases and 50,000 deaths annually worldwide, but there are remarkable variations in the racial and geographic distributions [1]. Radiotherapy (RT), particularly intensity-modulated radiotherapy (IMRT), is the recommended treatment for non-metastatic disease [2]. Concurrent chemoradiotherapy (CCRT) with or without adjuvant chemotherapy (AC) is the primary regimen for patients with locoregionally advanced NPC $[3,4]$. However, patients with similar stages and histological classifications have different survival outcomes due to the heterogeneity of the tumor protein expression profiles. The development of novel tumor markers to stratify treatment outcomes might enable better prediction of patient prognosis, provide insight into the mechanisms responsible for treatment failure, and result in the identification of novel therapeutic targets.
The cytotoxic T-lymphocyte associated antigen-4 (CTLA-4) is a well-known activator of T cells [5, 6]. CTLA-4 is expressed on the surface of $\mathrm{T}$ cells upon activation and interacts with B7 ligands (CD80/CD86) expressed on antigen presenting cells to inhibit cell proliferation, cytokine (interleukin-2 and interferon) production, and cell cycle progression $[7,8]$. CD28 is a major $\mathrm{T}$ cell co-stimulatory receptor, the co-engagement of which can prevent anergy and cell death [9].

The prognostic role of CTLA4 has been explored in several types of cancers. For example, CTLA4 overexpression was detected in non-squamous type non-small cell lung cancer and was associated with a reduced death rate [10]. Breast cancer patients with higher CTLA-4 mRNA levels had obvious axillary lymph node metastases and a higher clinical stage [11]. CTLA4 downregulation led to a significant increase in the proliferation and survival of chronic lymphocytic leukemia cells [12]. CD28 expression has 
been reported to correlate with tumor progression in multiple myeloma [13, 14]. However, no studies have addressed the prognostic value of CTLA4 and CD28 expression in NPC.

In the present study, we recruited NPC patients who were treated with cisplatin-based CCRT and investigated the expression of CTLA4 and CD28 in NPC tissue. We hypothesized that the expression of CTLA4 and CD28 could be of potential prognostic value for patients with NPC.

\section{RESULTS}

\section{Patient characteristics and immunohistochemical analysis}

The study included 44 women (44 of 191 patients, $23.0 \%$ ) and 147 men (147 of 191 patients, $77.0 \%$ ) with a median age of 50 years (range 19-79). Five (2.6\%) patients were classified as stage I, $22(11.5 \%)$ as stage II, $78(40.8 \%)$ as stage III, $74(38.7 \%)$ as stage IVa or IVb, and $12(6.3 \%)$ as stage IVc. Six (3.1\%) patients were classified as World Health Organization (WHO) II and 185 (96.9\%) as WHO III.

CTLA-4 expression with different intensities in the tumor cell cytoplasm (Figure 1) was observed in $186(97.4 \%)$ patients. CTLA-4 expression with different intensities in the lymphocyte cytoplasm (Figure 1) was observed in 185 (96.9\%) patients. Finally, CD28 expression with different intensities in the tumor cell cytoplasm (Figure 2) was observed in 187 (97.9\%) patients, and CD28 expression with different intensities in the lymphocyte cytoplasm (Figure 2) was observed in 178 $(93.2 \%)$ patients.

The final CTLA-4 or CD28 score was calculated as the proportion score $\times$ staining intensity. The median tumor CTLA-4 score was 2, the median lymphocyte CTLA-4 score was 0.7 , the median tumor CD28 score was 1 , and the median lymphocyte CD28 score was 0.7. When the CTLA-4 score of the tumor was 2 or higher, patients were considered to have high expression (present in 98 of 191 patients). When the CTLA-4 score of the lymphocytes was 0.7 or higher, the patients were considered to have high expression (present in 101 of 191 patients). A CD28 score of the tumor greater than or equal to 1 was observed in 126 of 191 patients, and these patients were considered to have high expression. The CD28 score of the lymphocytes in 96 of 191 patients with detec table expression was greater than or equal to 0.7 , and these patients were assigned to the high expression group. In the present study, the baseline characteristics of the CTLA-4 or CD28 high and low expression groups are shown in Table 1.

The association study showed that the expression of CTLA-4 in the tumor was significantly associated with the
UICC stage. The low tumor CTLA-4 expression group had more early stage (stage I-II) patients than the CTLA-4 high expression group ( $18.3 \%$ vs. $10.2 \%, p=0.047)$. Moreover, the low lymphocyte CTLA-4 expression group had fewer WHO II patients than the CTLA-4 high expression group ( $0 \%$ vs. $5.9 \%, p=0.003$ ). The association study showed that CTLA-4 or CD28 expression in the tumor or lymphocytes was not significantly associated with any of the other clinicopathological features examined including age, gender, UICC stage or WHO pathological type of the patients (Table 1).

\section{Correlation between CTLA-4 or CD28 expression in the tumor or lymphocytes and the clinical outcomes of NPC patients}

The 3-year overall survival (OS), failure-free survival (FFS), locoregional failure-free survival (LR-FFS) and distant failure-free survival (D-FFS) rates for the CTLA-4 or CD28 high and low expression groups are shown in Tables 2 and 3. The 3-year OS in the low tumor CTLA-4 expression group was higher than that in the high tumor CTLA-4 expression group (91.4\% vs. $81.2 \%$, $p=0.043$ ) (Figure 3A). The 3-year FFS in the low tumor CTLA-4 expression group was also higher than that in the high tumor CTLA-4 expression group (82.8\% vs. 68.0\%, $p=0.009$ ) (Figure 3B). Moreover, the 3 -year D-FFS in the low tumor CTLA-4 expression group was higher than that in the high tumor CTLA-4 expression group (85.8\% vs. $72.3 \%, p=0.006$ ) (Figure $3 \mathrm{C}$ ). There were no significant differences in the LR-FFS between the high and low tumor CTLA-4 expression groups. In addition, no significant differences in the OS, FFS, D-FFS, or LR-FFS were observed between the high and low lymphocyte CTLA-4 expression groups, high and low tumor CD28 expression groups, or high and low lymphocyte CD28 expression groups (Tables 2 and 3 ).

In the present study, a Cox regression analysis (Table 4) showed that the UICC stage was a significant prognostic factor that affected OS $(p=0.030)$. Body mass index (BMI) and C-reactive protein (CRP) level were also significant prognostic factors $(p<0.001$ and $p=0.001$, respectively). Tumor CTLA-4 expression was a marginally significant prognostic factor for FFS $(p=0.066)$. The UICC stage was a significant prognostic factor $(p<0.001)$ and the CRP level was a significant prognostic factor $(p=0.022)$. Tumor CTLA-4 expression was a significant prognostic factor for D-FFS ( $p=0.044)$, and the UICC and CRP level were also significant prognostic factors $(p<0.001$ and $p=0.005$, respectively). No significant prognostic factors were found for LR-FFS. In addition, lymphocyte CTLA-4 expression (Supplementary Table 1), tumor CD28 expression (Supplementary Table 2), and lymphocyte CD28 expression (Supplementary Table 3) were not significant prognostic factors for OS, FFS, D-FFS, or LR-FFS. 

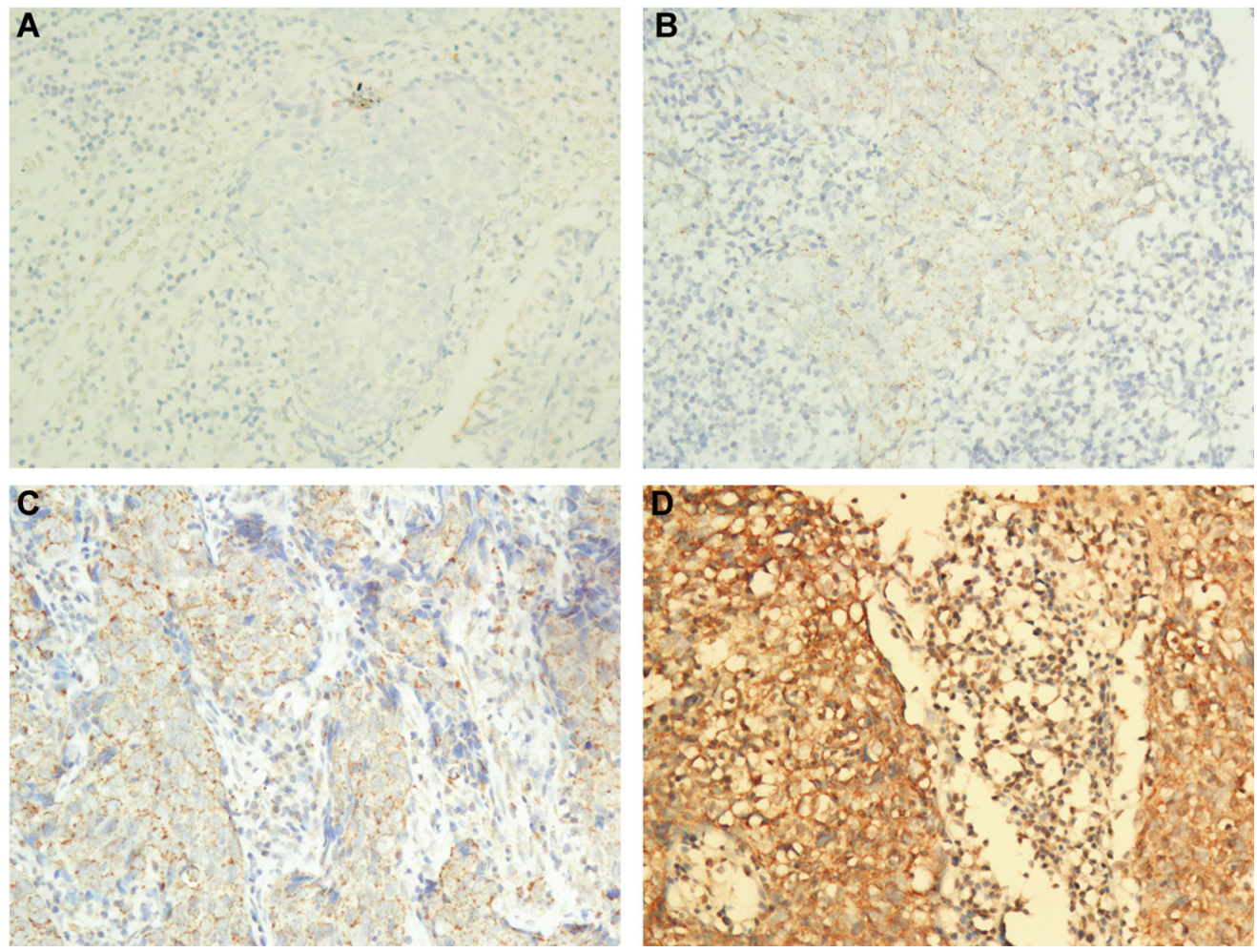

Figure 1: Representative images of the different intensities of the IHC staining for CTLA-4 expression. (A) Negative staining of CTLA-4 in NPC tumor and lymphocyte $(200 \times)$; $(\mathbf{B})$ Weak staining of CTLA-4 in NPC tumor and lymphocyte $(200 \times)$; $(\mathbf{C})$ Moderate staining of CTLA-4 in NPC tumor and lymphocyte $(200 \times)$; (D) Strong staining of CTLA-4 in NPC tumor and lymphocyte $(200 \times)$.
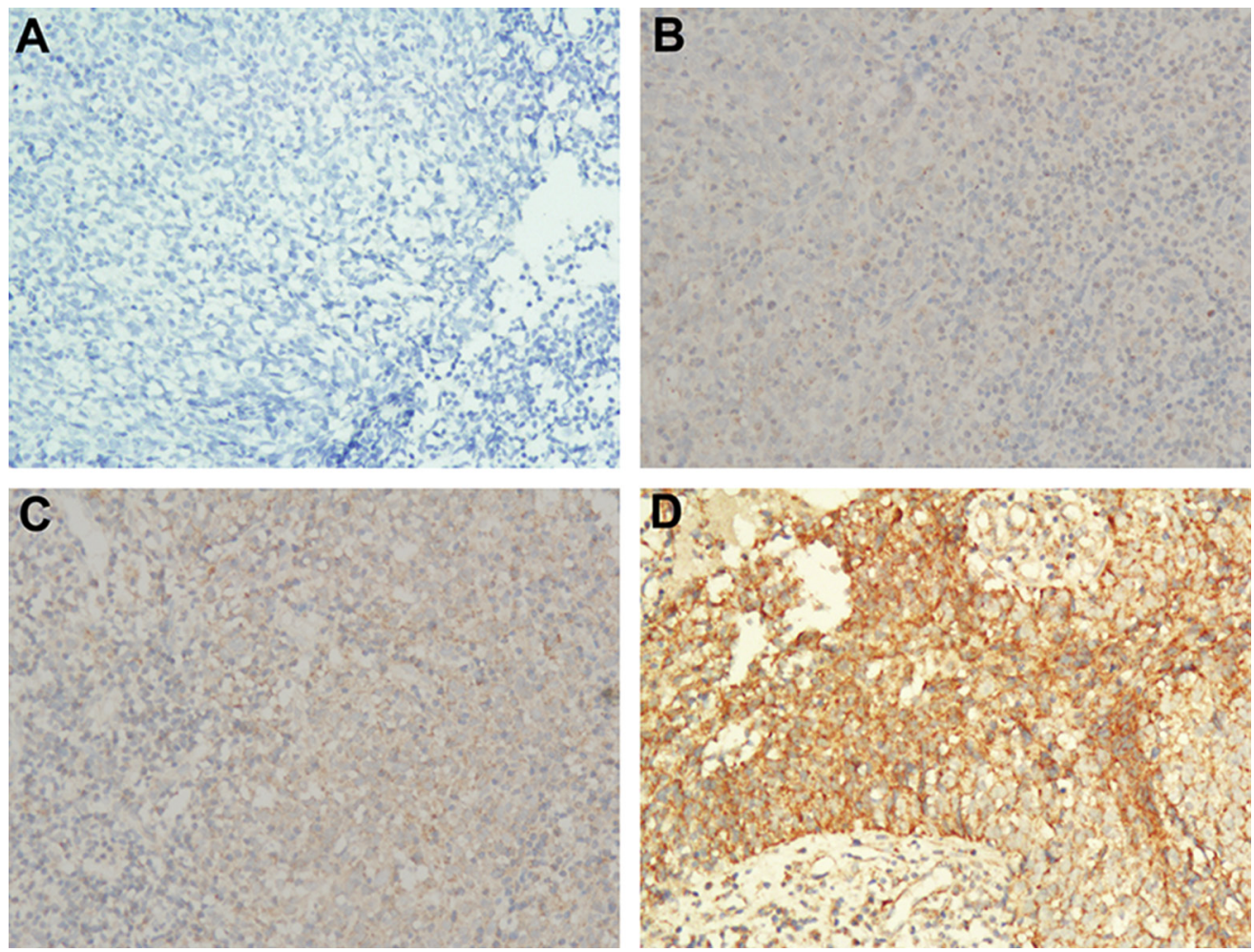

Figure 2: Representative images of the different intensities of IHC staining for CD28 expression. (A) Negative staining of CD28 in NPC tumor and lymphocyte $(200 \times)$; (B) Weak staining of CD28 in NPC tumor and lymphocyte $(200 \times)$; (C) Moderate staining of CD28 in NPC tumor and lymphocyte $(200 \times)$; (D) Strong staining of CD28 in NPC tumor and lymphocyte $(200 \times)$. 
Table 1: Baseline characteristics of the patients in the different CTLA-4 and CD28 groups

\begin{tabular}{|c|c|c|c|c|c|c|c|c|c|c|c|c|}
\hline & $\begin{array}{c}\text { Tumor } \\
\text { CTLA-4 } \\
\text { low } \\
\text { expression } \\
(n=93)\end{array}$ & $\begin{array}{c}\text { Tumor } \\
\text { CTLA-4 } \\
\text { high } \\
\text { expression } \\
(n=98)\end{array}$ & $\begin{array}{c}p \\
\text { value }\end{array}$ & $\begin{array}{c}\text { Lymphocyte } \\
\text { CTLA-4 low } \\
\text { expression } \\
(n=90)\end{array}$ & $\begin{array}{l}\text { Lymphocyte } \\
\text { CTLA-4 } \\
\text { high } \\
\text { expression } \\
(n=101)\end{array}$ & $\begin{array}{c}p \\
\text { value }\end{array}$ & $\begin{array}{c}\text { Tumor } \\
\text { CD28 } \\
\text { low } \\
\text { expression } \\
(n=65)\end{array}$ & $\begin{array}{c}\text { Tumor } \\
\text { CD28 high } \\
\text { expression } \\
(n=126)\end{array}$ & $\begin{array}{c}p \\
\text { value }\end{array}$ & $\begin{array}{c}\text { Lymphocyte } \\
\text { CD28 } \\
\text { low } \\
\text { expression } \\
(n=95)\end{array}$ & $\begin{array}{l}\text { Lymphocyte } \\
\text { CD28 high } \\
\text { expression } \\
(n=96)\end{array}$ & $\begin{array}{c}p \\
\text { value }\end{array}$ \\
\hline $\begin{array}{l}\text { Age [mean } \\
\text { (range)] }\end{array}$ & $\begin{array}{c}47.5 \\
(19-79)\end{array}$ & $\begin{array}{c}50.4 \\
(20-78)\end{array}$ & 0.115 & $48.6(19-79)$ & $49.3(20-78)$ & 0.704 & $\begin{array}{c}48.7 \\
(25-79)\end{array}$ & 49.5 (19-76) & 0.824 & $48.4(20-79)$ & $49.6(19-76)$ & 0.498 \\
\hline \multicolumn{13}{|l|}{ Age } \\
\hline$\geq 50$ & 41 & 55 & 0.096 & 41 & 55 & 0.219 & 33 & 63 & 0.920 & 47 & 49 & 0.828 \\
\hline$<50$ & 52 & 43 & & 49 & 46 & & 32 & 63 & & 48 & 47 & \\
\hline Sex & & & 0.219 & & & 0.261 & & & 0.462 & & & 0.157 \\
\hline Male & $68(73.1 \%)$ & $79(80.6 \%)$ & & $66(73.3 \%)$ & $81(80.2 \%)$ & & $48(73.8 \%)$ & $99(78.6 \%)$ & & $69(72.6 \%)$ & $78(81.3 \%)$ & \\
\hline Female & $25(26.9 \%)$ & $19(19.4 \%)$ & & $24(26.7 \%)$ & $20(19.8 \%)$ & & $17(26.2 \%)$ & $27(21.4 \%)$ & & $26(27.4 \%)$ & $18(18.8 \%)$ & \\
\hline Stage & & & 0.047 & & & 0.803 & & & 0.088 & & & 0.225 \\
\hline $\begin{array}{l}\text { I } \\
\text { II } \\
\text { III } \\
\text { IVa or IVb }\end{array}$ & $\begin{array}{c}4(4.3 \%) \\
13(14.0 \%) \\
39(41.9 \%) \\
34(36.6 \%)\end{array}$ & $\begin{array}{c}1(1.0 \%) \\
9(9.2 \%) \\
39(39.8 \%) \\
40(40.8 \%)\end{array}$ & & $\begin{array}{c}1(1.1 \%) \\
11(12.2 \%) \\
39(43.3 \%) \\
34(37.8 \%)\end{array}$ & $\begin{array}{c}4(4.0 \%) \\
11(10.9 \%) \\
39(38.6 \%) \\
40(39.6 \%)\end{array}$ & & $\begin{array}{c}1(1.5 \%) \\
11(16.9 \%) \\
29(44.6 \%) \\
21(32.3 \%)\end{array}$ & $\begin{array}{c}4(3.2 \%) \\
11(8.7 \%) \\
49(38.9 \%) \\
53(42.1 \%)\end{array}$ & & $\begin{array}{c}2(2.1 \%) \\
13(13.7 \%) \\
42(44.2 \%) \\
32(33.7 \%)\end{array}$ & $\begin{array}{c}3(3.1 \%) \\
9(9.4 \%) \\
36(37.5 \%) \\
42(43.8 \%)\end{array}$ & \\
\hline IVc & $3(3.2 \%)$ & $9(9.2 \%)$ & & $5(5.6 \%)$ & $7(6.9 \%)$ & & $3(4.6 \%)$ & $9(7.1 \%)$ & & $6(6.3 \%)$ & $6(6.3 \%)$ & \\
\hline WHO type & & & 0.727 & & & 0.003 & & & 0.218 & & & 0.399 \\
\hline $\begin{array}{l}\text { II } \\
\text { III }\end{array}$ & $\begin{array}{c}2(2.2 \%) \\
91(97.8 \%)\end{array}$ & $\begin{array}{c}4(4.1 \%) \\
94(95.9 \%)\end{array}$ & & $\begin{array}{c}0 \\
90(100.0 \%)\end{array}$ & $\begin{array}{c}6(5.9 \%) \\
95(94.1 \%)\end{array}$ & & $\begin{array}{c}3(4.6 \%) \\
62(95.4 \%)\end{array}$ & $\begin{array}{c}3(2.4 \%) \\
123(97.6 \%)\end{array}$ & & $\begin{array}{c}4(4.2 \%) \\
91(95.8 \%)\end{array}$ & $\begin{array}{c}2(2.1 \%) \\
94(97.9 \%)\end{array}$ & \\
\hline
\end{tabular}

Abbreviations: $\mathrm{WHO}=$ World Health Organization.

\section{DISCUSSION}

NPC is one of the Epstein-Barr virus (EBV)associated malignancies with distinct epidemiology, etiology, and clinical biological behavior compared to other head and neck cancers [15]. Identifying the patients who have the potential for immune escape and a greater risk of primary treatment failure is very important. In the present study, the co-expression of CD28 and CTLA-4 on both tumor cells and tumor-infiltrating lymphocytes (TILs) was detected. Furthermore, the impact of CD28 and CTLA-4 expression together with various clinical parameters on the survival of a cohort of NPC patients was assessed. To the best of our knowledge, this is the first study to explore the prognostic value of the co-expression of these two immune markers in NPC patients.

The expression of immunosuppressive proteins in cancer appears to help the tumor escape host immune surveillance, while the expression of immunosuppressive proteins in the immune cells around the tumor appears to be a host response to the tumor [16]. However, the clinical significance of the existence of immunosuppressive proteins in both tumors and immune cells in the tumor microenvironment is still controversial, and their potential as prognostic markers and therapeutic targets needs to be investigated.
CLTA-4, one of the most important immunosuppressive proteins that acts via interactions with its ligands CD80 and CD86, plays a key role in attenuating the early activation of naïve and memory $\mathrm{T}$ cells [17]. Kim et al. [16] found that in gastric cancer, the expression of immunosuppressive proteins, including PD-L1, CTLA-4, and IDO, in tumors was associated with less advanced stage, intestinal type, and well/moderately differentiated adenocarcinoma. Although there was no statistical significance, better prognoses were also noted for gastric cancer patients with CTLA-4 expression in the tumors. A CTLA-4 polymorphism analysis conducted by Xiao et al. [18] showed that CTLA-4 single nucleotide polymorphisms were highly associated with NPC susceptibility in a Chinese population. However, no previous studies have examined whether CTLA-4 expression influences the prognosis of NPC patients.

CD28 is normally expressed on $95 \%$ of CD4+ T cells and approximately $50 \%$ of CD $8+\mathrm{T}$ cells in human peripheral blood [19]. It plays a key role as a co-stimulatory signal during antigen/major histocompatibility complex presentation [20]. Decreased CD28 expression has been observed in some types of cancer, for example, in the dysfunctional peripheral T-lymphocytes from patients with hairy cell leukemia [21] and chronic lymphocytic leukemia [22], as well as in colorectal cancer patients [23]. However, 
Table 2: The different survival results in the different tumor CTLA-4 and lymphocyte CTLA-4 expression groups

\begin{tabular}{|c|c|c|c|c|c|c|}
\hline & \multicolumn{2}{|c|}{ Tumor CTLA-4 } & \multicolumn{4}{|c|}{ Lymphocyte CTLA-4 } \\
\hline & Low expression & High expression & $P$ value & Low expression & High expression & $P$ value \\
\hline 3-year OS & $91.4 \%$ & $81.2 \%$ & 0.043 & $90.0 \%$ & $82.7 \%$ & 0.300 \\
\hline 3-year FFS & $82.8 \%$ & $68.0 \%$ & 0.009 & $79.9 \%$ & $71.1 \%$ & 0.091 \\
\hline 3-year D-FFS & $85.8 \%$ & $72.3 \%$ & 0.006 & $84.2 \%$ & $74.1 \%$ & 0.077 \\
\hline 3-year LR-FFS & $93.2 \%$ & $94.3 \%$ & 0.746 & $92.9 \%$ & $94.6 \%$ & 0.668 \\
\hline
\end{tabular}

Abbreviations: OS, overall survival; FFS, failure free survival; D-FFS, distant failure-free survival; LR-FFS, localregional failure-free survival.

\begin{tabular}{|c|c|c|c|c|c|c|}
\hline & \multicolumn{2}{|c|}{ Tumor CD28 } & \multicolumn{4}{|c|}{ Lymphocyte CD28 } \\
\hline & $\begin{array}{c}\text { Low } \\
\text { expression }\end{array}$ & High expression & $P$ value & $\begin{array}{c}\text { Low } \\
\text { expression }\end{array}$ & High expression & $P$ value \\
\hline 3-year OS & $85.7 \%$ & $86.5 \%$ & 0.695 & $87.1 \%$ & $85.3 \%$ & 0.779 \\
\hline 3-year FFS & $76.4 \%$ & $73.7 \%$ & 0.752 & $75.5 \%$ & $73.8 \%$ & 0.849 \\
\hline 3-year D-FFS & $82.8 \%$ & $76.9 \%$ & 0.505 & $78.6 \%$ & $77.9 \%$ & 0.812 \\
\hline 3-year LR-FFS & $91.7 \%$ & $94.8 \%$ & 0.409 & $94.3 \%$ & $93.2 \%$ & 0.777 \\
\hline
\end{tabular}

Abbreviations: OS, overall survival; FFS, failure free survival; D-FFS, distant failure-free survival; LR-FFS, localregional failure-free survival.

whether CD28 expression on TILs or tumor cells influences the prognosis of NPC patients has not been evaluated.

In the present study, we found that the 3-year OS, FFS, and D-FFS in the low tumor CTLA-4 expression group were significantly higher than those in the high tumor CTLA-4 expression group, although the low tumor CTLA-4 expression group had more early stage (stage I-II) patients than the high CTLA-4 expression group $(18.3 \%$ vs. $10.2 \%, p=0.047)$. After adjusting for the UICC stage and other important factors including gender, age, smoking status, first-degree family history of NPC, BMI, and CRP level, a Cox regression analysis confirmed the prognostic value of the tumor CTLA-4 expression, particularly the D-FFS, in NPC patients. However, no significant association between CTLA-4 expression on TILs and clinical outcomes was observed. Additionally, there was no apparent association between CD28 expression on tumor cells or TILs and clinical outcomes.

$\mathrm{T}$ cell activation and suppression require the interaction between B7 on an antigen-presenting cell and CD28 or CTLA- 4 on a T cell. Immediately after activation, CTLA- 4 translocates to the plasma membrane where it downregulates the functions of $\mathrm{T}$ cells to maintain immunological homeostasis [24]. Pistillo et al. [25] found that CTLA-4 was not restricted to the lymphoid cell lineage and could be a target to induce apoptosis in leukemic cells. In acute B and T cell leukemias, the CTLA-4 expression was mainly cytoplasmic, while in chronic B cell leukemias, it was expressed on both the cell surface and in the cytoplasm. Chronic T-cell leukemias were found to be negative for CTLA-4 in a few cases. In solid tumors, cytoplasmic and surface CTLA-4 expression was detected in all six osteosarcoma specimens and in all five cases of ductal breast carcinomas examined. In gastric cancer [16], CTLA-4 was expressed in the cytoplasm of tumor cells. In the present study of NPC, CTLA-4 expression was found not only in TILs but also in tumor cells. In NPC cells, CTLA-4 was almost exclusively expressed in the cytoplasm. This was also true of the TILs in NPC, which is consistent with the fact that the majority of CTLA-4 is localized in vesicles of the Golgi apparatus and is released to the cell surface during $\mathrm{T}$ cell activation $[15,26]$. Only small amounts of CTLA-4 can be detected on the cell surface at any given time, even following T-cell activation [26].

The intracellular trafficking pathways that control the transport of CTLA-4 to the cell surface influence the degree of inhibition and the potency of antibody checkpoint blockade in cancer immunotherapy. This mechanism may at least partly explain why the density and intensity of CTLA-4 expression in the cytoplasm of 
the TILs did not have a significant correlation with the prognosis of NPC patients in our study.

Recent studies have confirmed the survival benefit of ipilimumab (a monoclonal antibody that targets CTLA-4) in patients with advanced melanoma [27] and non-smallcell lung cancer [28]. However, the potential therapeutic effects of ipilimumab against other solid tumors such as NPC have not been investigated. At present, although no single immunological or tumor-related factor has been found to solely determine the response to an immunotherapeutic agent [29], the expression of CTLA-4 in the tumor or TILs may represent a target, and CTLA-4 blockade may provide therapeutic benefits for NPC.

Although we did not find any correlation between the lymphocyte CTLA-4 expression and NPC patient clinical outcome in our study, we did find that the OS, FFS, and D-FFS rates in the low tumor CTLA-4 expression group were significantly higher than those in the high tumor CTLA-4 expression group. A Cox regression analysis confirmed the prognostic value of the tumor CTLA-4 expression in NPC patients, especially for the D-FFS of NPC patients.
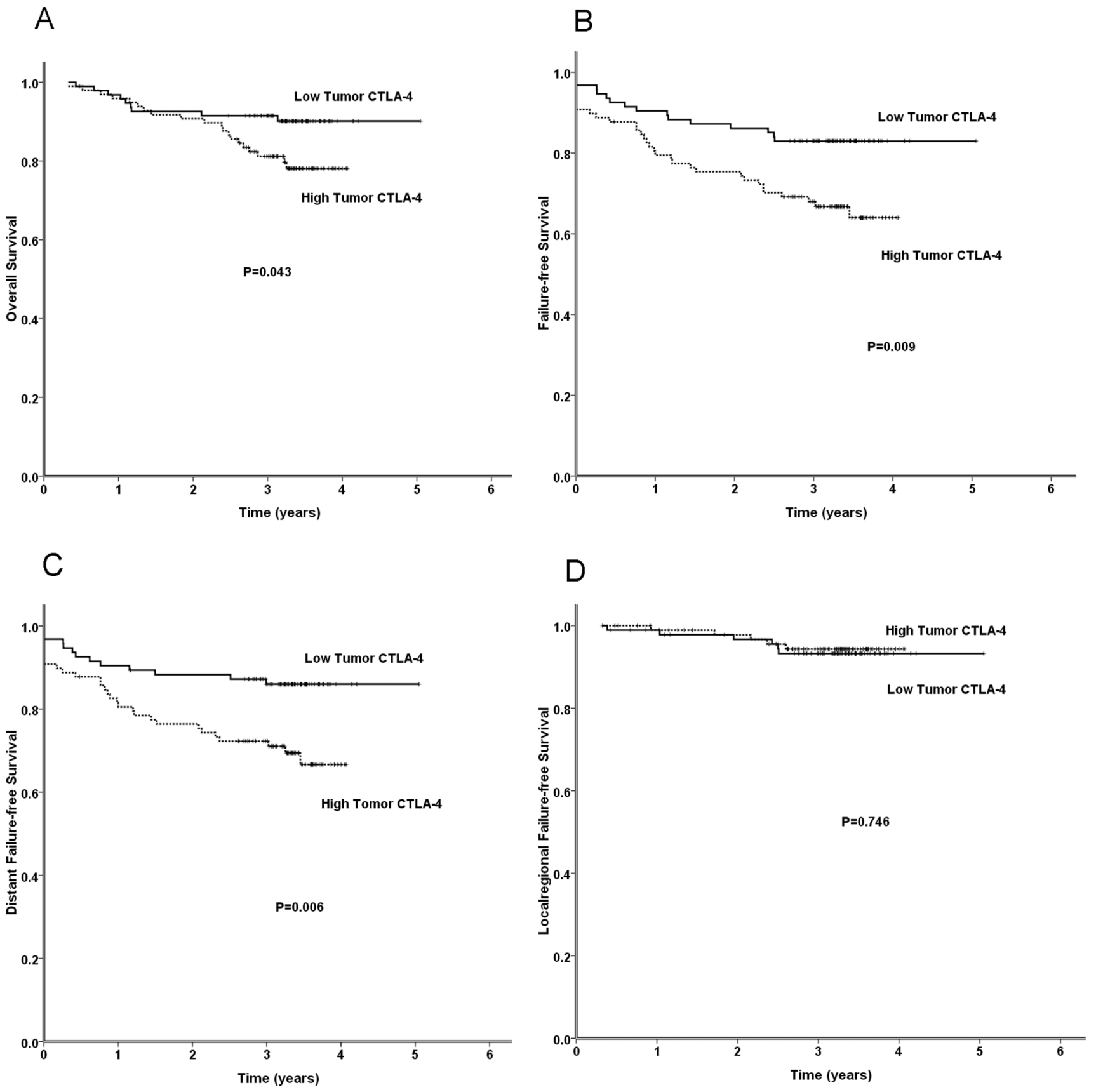

Figure 3: The results of a comparison between the low and high tumor CTLA-4 expression groups with regard to the OS, FFS, D-FFS, and LR-FFS rates. 
Table 4: The significant factors associated with the survival of NPC patients identified in a multivariate analysis that included the tumor CTLA-4 expression

\begin{tabular}{|c|c|c|c|c|c|c|c|c|c|c|c|c|}
\hline \multirow{2}{*}{ Characteristics } & \multicolumn{3}{|c|}{ OS } & \multicolumn{3}{|c|}{ FFS } & \multicolumn{3}{|c|}{ D-FFS } & \multicolumn{3}{|c|}{ LR-FFS } \\
\hline & HR & $95 \%$ CI & Pvalue & HR & $95 \%$ CI & $\begin{array}{c}P \\
\text { value }\end{array}$ & HR & $95 \%$ CI & Pvalue & HR & $95 \%$ CI & $\begin{array}{c}P \\
\text { value }\end{array}$ \\
\hline Tumor CTLA-4 & 2.069 & $0.929-4.606$ & 0.075 & 1.769 & $0.964-3.247$ & 0.066 & 1.992 & $1.020-3.891$ & 0.044 & $*$ & & \\
\hline BMI & 0.762 & $0.661-0.879$ & 0.000 & 0.914 & $0.828-1.008$ & 0.071 & $*$ & & & 0.819 & $0.665-1.008$ & 0.059 \\
\hline UICC stage & 1.765 & $1.057-2.948$ & 0.030 & 5.207 & $2.849-9.518$ & 0.000 & 6.528 & $3.370-12.649$ & 0.000 & 2.029 & $0.906-4.544$ & 0.085 \\
\hline CRP & 1.047 & $1.020-1.075$ & 0.001 & 1.027 & $1.004-1.050$ & 0.022 & 1.032 & $1.009-1.055$ & 0.005 & $*$ & & \\
\hline
\end{tabular}

Abbreviations: OS, overall survival; FFS, failure free survival; D-FFS, distant failure-free survival; LR-FFS, localregional failure-free survival.* Not a significant factor.

In conclusion, NPC patients with high tumor CTLA4 expression had a poor prognosis. This group of patients might be ideal for a clinical trial of anti-CTLA-4 therapy.

\section{MATERIALS AND METHODS}

\section{Ethics statement}

The Institutional Review Board of Sun Yat-Sen Cancer Center approved this study protocol. Written informed consent was obtained from patients for the collection of the tissue samples.

\section{Patient recruitment and follow-up}

The expression of CTLA- 4 and CD28 in tumor cells was evaluated in tumor samples obtained before treatment from 191 previously untreated, histologically confirmed, stage I-IVc (according to the 7th edition of the AJCC/UICC criteria), WHO II-III NPC patients who were prospectively enrolled between January 2010 and November 2011. Among the enrolled patients, 147 were male and 44 were female, with a sex ratio of 3.3:1. The median age of the patients was 50 years (range, 19-79 years). The radiation technique used was IMRT, which was performed in accordance with the treatment policy for NPC at Sun Yat-Sen University Cancer Center. For non-metastatic disease, the treatment regimens included (a) RT alone, (b) CCRT, (c) induction chemotherapy (IC) + CCRT, and (d) CCRT + AC. The regimen used for IC was PF (cisplatin $80-100 \mathrm{mg} / \mathrm{m}^{2}$ intravenously (IV) on day 1 and 5 - Fu $800 \mathrm{mg} / \mathrm{m}^{2} / \mathrm{d}$ continuously IV on days $1-5$ ). The treatment regimens were repeated every 3 weeks for two to three cycles. Concurrent chemotherapy primarily consisted of the following two regimens: cisplatin $80-100 \mathrm{mg} / \mathrm{m}^{2}$ IV every 3 weeks and cisplatin $30-40 \mathrm{mg} / \mathrm{m}^{2}$ IV weekly. The adjuvant chemotherapy regimen was $\mathrm{PF}$ (cisplatin $80 \mathrm{mg} / \mathrm{m}^{2} \mathrm{IV}$ on day 1 and 5 -Fu $800 \mathrm{mg} / \mathrm{m}^{2} / \mathrm{d}$ continuously IV on days 1-5). Adjuvant chemotherapy was repeated every 4 weeks for three cycles. Palliative chemotherapy was administered to patients with metastatic disease. After the completion of treatment, patients were followed up monthly for the first 3 months, every 3 months through 3 years, every 6 months for the next 2 years, and then annually thereafter. The median follow-up was 3.4 years (range, $0.3-5.1$ years).

\section{Immunohistochemistry}

Antibodies were subjected to in-house validation by the manufacturer for IHC analysis on paraffin-embedded material. The antibodies used in the study were CD152 (Rabbit; 251548; Abbiotec, San Diego, California, U.S.A.) and CD28 (Rabbit; 251660; Abbiotec). Tissue sections were deparaffinized with xylene and rehydrated with ethanol. Hydrogen peroxide (3\%) was used to remove endogenous peroxidase. Antigen retrieval was performed in $0.01 \mathrm{mmol} / \mathrm{L}$ sodium citrate buffer ( $\mathrm{pH} \mathrm{6.0)}$ ) for $5 \mathrm{~min}$ in a microwave. The samples were incubated with the primary antibodies for 30 minutes at $37^{\circ} \mathrm{C}$. The sections were then washed with PBS and incubated with secondary antibodies (EnVision, Dako, Carpinteria, CA, U.S.A.) for 120 minutes at $37^{\circ} \mathrm{C}$. The antigens were visualized with 3,3'-Diaminobenzidine. Sections were counterstained with hematoxylin. Hydrochloric acid alcohol was used for differentiation. Lithium carbonate was used to turn the slices back to blue.

\section{Scoring of the immunohistochemistry findings}

The expression of CTLA4 and CD28 was scored by combining (a) the percentage of positively stained cells determined using light microscopy (a proportion score was assigned [i.e., tumors with $50 \%$ of the cytoplasm stained were assigned a score of 0.5$]$ ) with (b) the intensity of staining $(0$, negative staining; 1 , mild staining; 2 , moderate staining; 3 , strong staining). The final score was assessed as a $\times$ b. All specimens were evaluated by two independent pathologists without prior knowledge of the clinical origin of the specimen. The values were accepted if the results reported by the pathologists were consistent. In cases for which the results were inconsistent, the pathologists worked to reach a compromise on the score. 


\section{Statistical analysis}

The Statistical Package for Social Sciences version 16.0 software program (SPSS Inc., Chicago, IL, U.S.A.) was used for the analysis. A chi-squared analysis was used to compare the incidence rates and categorical variables. The means of continuous variables were compared using Student's $t$-tests. The survival rates were calculated using the Kaplan-Meier method and were compared using log-rank tests. Multivariate analyses were performed using the Cox proportional hazards model. Hazard ratio point and interval $(95 \%$ confidence interval) estimates were computed using the Cox proportional hazards model. The potentially important prognostic factors that were considered in the modeling process were the following: patient gender, age, smoking status, first-degree family history of NPC, BMI, UICC stage, CRP level, and CTLA-4 or CD28 expression in the tumor or lymphocytes.

The smoking status at diagnosis was categorized into three groups: (a) never-smokers, which referred to patients who had never smoked; (b) ex-smokers, which referred to former smokers who had stopped smoking, and (c) smokers who continued smoking until the day of the diagnosis of NPC. All of the $p$ values were twosided, and $p<0.05$ was considered to be statistically significant.

\section{ACKNOWLEDGMENTS}

This work was supported by the National Natural Science Foundation of China (No. 81425018 and No. 81072226), 863 Project (No. 2012AA02A501 and No. 2012AA02A206), National Key Basic Research Program of China (No. 2013CB910304), Sci-Tech Project Foundation of Guangdong Province (No. 2014A 020212103), Special Support Plan of Guangdong Province (No. 2014TX01R145), Sci-Tech Project Foundation of Guangzhou City (No. 2011J4300100), Sci-Tech Project Foundation of Guangdong Province (No. 2011B031800161), National Natural Science Foundation of China (No. 81201629) and Fundamental Research Funds for the Central Universities, Sun Yat-Sen University Clinical Research 5010 Program (No.201315 and No.2015010), the Fundamental Research Funds for the Central Universities ((No. 15ykpy36)), Clinical Research of Special Funds of Wu Jieping Medical Foundation (No.320.6750.14270), CSCO-Merck Serono Oncology Research Fund (No.Y-MT2015-023), China Scholarship Council (No.201506385044).

\section{CONFLICTS OF INTEREST}

The authors declare that there are no potential conflicts of interest.

\section{REFERENCES}

1. Ferlay J, Shin HR, Bray F, Forman D, Mathers C, Parkin DM. Estimates of worldwide burden of cancer in 2008: GLOBOCAN 2008. Int J Cancer. 2010; 127:2893-2917.

2. Peng G, Wang T, Yang KY, Zhang S, Zhang T, Li Q, Han J, $\mathrm{Wu} \mathrm{G}$. A prospective, randomized study comparing outcomes and toxicities of intensity-modulated radiotherapy vs. conventional two-dimensional radiotherapy for the treatment of nasopharyngeal carcinoma. Radiother Oncol. 2012; 104:286-293.

3. Baujat B, Audry H, Bourhis J, Chan AT, Onat H, Chua DT, Kwong DL, Al-Sarraf M, Chi KH, Hareyama M, Leung SF, Thephamongkhol K, Pignon JP. Chemotherapy in locally advanced nasopharyngeal carcinoma: an individual patient data meta-analysis of eight randomized trials and 1753 patients. Int J Radiat Oncol Biol Phys. 2006; 64:47-56.

4. Langendijk JA, Leemans CR, Buter J, Berkhof J, Slotman BJ. The additional value of chemotherapy to radiotherapy in locally advanced nasopharyngeal carcinoma: a meta-analysis of the published literature. J Clin Oncol. 2004; 22:4604-4612.

5. Tivol EA, Borriello F, Schweitzer AN, Lynch WP, Bluestone JA, Sharpe AH. Loss of CTLA-4 leads to massive lymphoproliferation and fatal multiorgan tissue destruction, revealing a critical negative regulatory role of CTLA-4. Immunity. 1995; 3:541-547.

6. Waterhouse P, Penninger JM, Timms E, Wakeham A, Shahinian A, Lee KP, Thompson CB, Griesser H, Mak TW. Lymphoproliferative disorders with early lethality in mice deficient in Ctla-4. Science. 1995; 270:985-988.

7. Krummel MF, Allison JP. CTLA-4 engagement inhibits IL-2 accumulation and cell cycle progression upon activation of resting T cells. J Exp Med. 1996; 183:2533-2540.

8. Brunner MC, Chambers CA, Chan FK, Hanke J, Winoto A, Allison JP. CTLA-4-Mediated inhibition of early events of T cell proliferation. J Immunol. 1999; 162:5813-5820.

9. Slavik JM, Hutchcroft JE, Bierer BE. CD28/CTLA-4 and CD80/CD86 families: signaling and function. Immunol Res. 1999; 19:1-24.

10. Salvi S, Fontana V, Boccardo S, Merlo DF, Margallo E, Laurent S, Morabito A, Rijavec E, Dal Bello MG, Mora M, Ratto GB, Grossi F, Truini M, et al. Evaluation of CTLA4 expression and relevance as a novel prognostic factor in patients with non-small cell lung cancer. Cancer Immunol Immun. 2012; 61:1463-1472.

11. Mao H, Zhang L, Yang Y, Zuo W, Bi Y, Gao W, Deng B, Sun J, Shao Q, Qu X. New insights of CTLA-4 into its biological function in breast cancer. Curr Cancer Drug Tar. 2010; 10:728-736.

12. Mittal AK, Chaturvedi NK, Rohlfsen RA, Gupta P, Joshi AD, Hegde GV, Bociek RG, Joshi SS. Role of CTLA4 in the proliferation and survival of chronic lymphocytic leukemia. PloS one. 2013; 8:e70352. 
13. Nair JR, Carlson LM, Koorella C, Rozanski CH, Byrne GE, Bergsagel PL, Shaughnessy JP, Jr., Boise LH, ChananKhan A, Lee KP. CD28 expressed on malignant plasma cells induces a prosurvival and immunosuppressive microenvironment. J Immunol. 2011; 187:1243-1253.

14. Robillard N, Jego G, Pellat-Deceunynck C, Pineau D, Puthier D, Mellerin MP, Barille S, Rapp MJ, Harousseau JL, Amiot M, Bataille R. CD28, a marker associated with tumoral expansion in multiple myeloma. Clin Cancer Res. 1998; 4:1521-1526.

15. Young LS, Dawson CW. Epstein-Barr virus and nasopharyngeal carcinoma. Chin J Cancer. 2014; 33: 581-590.

16. Kim JW, Nam KH, Ahn SH, Park DJ, Kim HH, Kim SH, Chang H, Lee JO, Kim YJ, Lee HS, Kim JH, Bang SM, Lee JS, Lee KW. Prognostic implications of immunosuppressive protein expression in tumors as well as immune cell infiltration within the tumor microenvironment in gastric cancer. Gastric Cancer. 2016; 19:42-52. doi: 10.1007/s10120-014-0440-5.

17. Callahan MK, Wolchok JD. At the bedside: CTLA-4and PD-1-blocking antibodies in cancer immunotherapy. J Leukoc Biol. 2013; 94:41-53.

18. Xiao M, Qi F, Chen X, Luo Z, Zhang L, Zheng C, Hu S, Jiang X, Zhou M, Tang J. Functional polymorphism of cytotoxic T-lymphocyte antigen 4 and nasopharyngeal carcinoma susceptibility in a Chinese population. Int $\mathrm{J}$ Immunogent. 2010; 37:27-32.

19. June CH, Ledbetter JA, Linsley PS, Thompson CB. Role of the CD28 receptor in T-cell activation. Immunol Today. 1990; 11:211-216.

20. Judge TA, Tang A, Turka LA. Immunosuppression through blockade of CD28:B7-mediated costimulatory signals. Immunol Res. 1996; 15:38-49.

21. van de Corput L, Falkenburg JH, Kester MG, Willemze R, Kluin-Nelemans JC. Impaired expression of CD28 on $\mathrm{T}$ cells in hairy cell leukemia. Clin Immunol. 1999; 93: 256-262.

22. Rossi E, Matutes E, Morilla R, Owusu-Ankomah K, Heffernan AM, Catovsky D. Zeta chain and CD28 are poorly expressed on $\mathrm{T}$ lymphocytes from chronic lymphocytic leukemia. Leukemia. 1996; 10:494-497.

23. Kruger K, Buning C, Schriever F. Activated T lymphocytes bind in situ to stromal tissue of colon carcinoma but lack adhesion to tumor cells. Eur J Immunol. 2001; 31:138-145.

24. Chan KC. Plasma Epstein-Barr virus DNA as a biomarker for nasopharyngeal carcinoma. Chin J Cancer. 2014; 33:598-603.

25. Pistillo MP, Tazzari PL, Palmisano GL, Pierri I, Bolognesi A, Ferlito F, Capanni P, Polito L, Ratta M, Pileri S, Piccioli M, Basso G, Rissotto L, et al. CTLA-4 is not restricted to the lymphoid cell lineage and can function as a target molecule for apoptosis induction of leukemic cells. Blood. 2003; 101:202-209.

26. Schneider H, Rudd CE. Diverse mechanisms regulate the surface expression of immunotherapeutic target ctla-4. Front Immunol. 2014; 5:619.

27. Hodi FS, O'Day SJ, McDermott DF, Weber RW, Sosman JA, Haanen JB, Gonzalez R, Robert C, Schadendorf D, Hassel JC, Akerley W, van den Eertwegh AJ, Lutzky J, et al. Improved survival with ipilimumab in patients with metastatic melanoma. N Engl J Med. 2010; 363:711-723.

28. Lynch TJ, Bondarenko I, Luft A, Serwatowski P, Barlesi F, Chacko R, Sebastian M, Neal J, Lu H, Cuillerot JM, Reck M. Ipilimumab in combination with paclitaxel and carboplatin as first-line treatment in stage IIIB/IV nonsmall-cell lung cancer: results from a randomized, doubleblind, multicenter phase II study. J Clin Oncol. 2012; 30:2046-2054.

29. Postow MA, Callahan MK, Wolchok JD. Immune Checkpoint Blockade in Cancer Therapy. J Clin Oncol. 2015; 33:1974-82. doi: 10.1200/JCO.2014.59.4358. 